\title{
Pulmonary Rehabilitation for Mild COPD: A Systematic Review
}

\author{
Cristina Jácome MSc and Alda Marques PhD
}

\begin{abstract}
BACKGROUND: Pulmonary rehabilitation (PR) is effective in improving exercise capacity and health-related quality of life (HRQOL) in patients with moderate-to-very-severe COPD. Quadriceps strength and HRQOL can be impaired in patients with mild COPD, therefore, patients at this grade may already benefit from PR. However, the impact of PR in patients with mild COPD remains unestablished. Thus, this systematic review assessed the impact of PR on exercise capacity, HRQOL, health-care resource use and lung function in patients with mild COPD. METHODS: The Web of Knowledge, EBSCO, MEDLINE, and SCOPUS databases were searched up to April 2013. Reviewers independently selected studies according to the eligibility criteria. RESULTS: Three studies with different designs (retrospective, one group pretest-posttest, and randomized controlled trial) were included. Out-patient PR programs were implemented in two studies, which included mainly aerobic, strength, and respiratory muscle training. The randomized controlled trial compared a PR home-based program, consisting of 6 months of walking and participating in ball games, with standard medical treatment. Significant improvements in exercise capacity (effect size [ES] 0.87-1.82) and HRQOL (ES 0.24-0.86) were found when comparing pretest-posttest data and when comparing PR with standard medical treatment. In one study, a significant decrease in hospitalization days was found (ES 0.38). No significant effects were observed on the number of emergency department visits (ES 0.32), number of hospitalizations (ES 0.219), or lung function (ES 0.198). CONCLUSIONS: Most of the PR programs had significant positive effects on exercise capacity and HRQOL in patients with mild COPD; however, their effects on health-care resource use and lung function were inconclusive. This systematic review suggests that patients with mild COPD may benefit from PR; however, insufficient evidence is still available. Studies with robust designs and with longer follow-up times should be conducted. Key words: pulmonary rehabilitation; mild chronic obstructive pulmonary disease; chronic obstructive pulmonary disease. [Respir Care 2014;59(4):588-594. (C) 2014 Daedalus Enterprises]
\end{abstract}

\section{Introduction}

COPD, independent of its severity, impacts the lives of patients and families as well as health-care systems. ${ }^{1,2}$

\footnotetext{
Ms Jácome is affiliated with the Research Centre in Physical Activity, Health and Leisure, Faculty of Sports, University of Porto, Porto, Portugal, and the School of Health Sciences, University of Aveiro, Aveiro, Portugal. Dr. Marques is affiliated with the School of Health Sciences, University of Aveiro, Aveiro, Portugal, and Unidade de Investigação e Formação sobre Adultos e Idosos, Porto, Portugal.

This study was supported by grant SFRH/BD/84665/2012 from Fundação para a Ciência e Tecnologia, Portugal.
}

The authors have disclosed no conflicts of interest.
Therefore, it is imperative to plan health care for patients with COPD at all grades.

Pulmonary rehabilitation is defined as "an evidencebased, multidisciplinary, and comprehensive intervention for patients with chronic respiratory diseases who are symptomatic and often have decreased daily life activities". ${ }^{3}$ This intervention is a recommended standard of care in the management of patients with COPD, and typically combines exercise training, education, and psychosocial sup-

\footnotetext{
Correspondence: Alda Marques PhD, School of Health Sciences, University of Aveiro (ESSUA), Agras do Crasto, Campus Universitário de Santiago, Edifício 30, 3810-193 Aveiro, Portugal. E-mail: amarques@ua.pt.
}

DOI: $10.4187 /$ respcare. 02742 
port. ${ }^{3,4}$ A meta-analysis conducted by Lacasse et al ${ }^{5}$ suggests that pulmonary rehabilitation is effective in relieving dyspnea and fatigue, and in improving patients' healthrelated quality of life (HRQOL). However, in this metaanalysis only studies including patients with moderate, severe, and very severe COPD were analyzed.

Recent evidence has shown that physical activity levels, quadriceps strength, and HRQOL can be already impaired in patients with mild COPD (best recorded $\mathrm{FEV}_{1}$ $\geq 80 \%$ predicted), ${ }^{6-8}$ and these impairments worsen over time. ${ }^{8}$ Therefore, patients at this grade may also benefit from pulmonary rehabilitation programs. A systematic review ${ }^{9}$ about the influence of physical activity on mild-tomoderate COPD showed that physical activity significantly improved patients' physical fitness; however, no statistically significant beneficial effects were seen on HRQOL or dyspnea. Furthermore, the great proportion of patients analyzed in this review had moderate COPD. Therefore, the impact of pulmonary rehabilitation programs on patients with mild COPD remains unestablished.

Thus, this systematic review aimed to assess the impact of pulmonary rehabilitation on exercise capacity, HRQOL, health-care resource use, and lung function in patients with mild COPD.

\section{Methods}

\section{Search Strategy}

A systematic literature search was conducted between January and April 2013 on the following databases: Web of Knowledge (1970-2013), EBSCO (1974-2013), MEDLINE (1948-2013), and SCOPUS (1960-2013). The search terms used were organized using the PICO (Population, Intervention, Comparison, and Outcome) framework, ${ }^{10}$ the definition of Comparison (C) was omitted as it was aimed at finding a range of study designs, as follows: "COPD" OR "chronic obstructive pulmonary disease" OR "chronic bronchitis" OR "emphysema" OR "mild COPD" OR "early COPD" OR "GOLD 1" OR "GOLD I" AND "pulmonary rehabilitation" OR "respiratory rehabilitation" OR "exercise training" OR "physical activity" OR "exercise" AND "exercise capacity" OR "health-related quality of life" OR "health-care resource use" OR "lung function" $\mathrm{OR}$ "FEV ${ }_{1}$ ". The reference lists of the included studies were hand searched for other potentially eligible studies. This systematic review was reported according to the PRISMA Group statement for preferred reporting items for systematic reviews and meta-analyses. ${ }^{11}$

\section{Selection Criteria}

According to the PICO framework, studies were included if they met the following inclusion criteria.
1. Patients with mild COPD $\left(\mathrm{FEV}_{1} \geq 80 \%\right.$ predicted $\left.^{6}\right)$

2. Pulmonary rehabilitation program (in-patient, out-patient, or home-based care) of at least 4 weeks ${ }^{4,5}$ that included exercise training with or without any form of education and/or psychological support

3. Comparison: Standard medical treatment or none

4. Outcomes: at least one of the following: exercise capacity, HRQOL, health-care resource use, and lung function

Studies were excluded if they did not include patients with mild COPD (studies with a subgroup of patients were retained in the analysis) and if they were review articles, abstracts of communications or meetings, conference proceedings papers, case reports, editorials, commentary to articles, study protocols, or unpublished papers. Papers without abstracts or written in languages other than English, Portuguese, and Spanish were also excluded.

\section{Screening of Studies}

The authors independently reviewed the titles, abstracts, and key words of every record. If the information given in the title, abstract, and/or key words suggested that the study might fit the inclusion criteria of the systematic review, the full article was retrieved for further assessment. From the full articles, the decision to exclude a study was based on the agreement of both authors. Disagreements were solved by reaching a consensus. Studies that did not fulfill the selection criteria of the systematic review were excluded. Once a study was excluded, a record of the article, including the reason for exclusion, was retained.

\section{Quality Assessment}

The methodological quality of each included study was independently assessed by the two authors, based on the checklist created by Downs and Black. ${ }^{12}$ This checklist assesses the quality of both randomized and non-randomized studies of health-care interventions, and it is composed of 27 questions split into 5 sections: reporting, external validity, internal validity-bias, internal validityconfounding, and power..$^{12}$ According to previous systematic reviews, ${ }^{13,14}$ the scoring for question 27 dealing with statistical power was simplified to a choice of awarding either 1 point or 0 points, depending on whether there was sufficient power to detect a clinically important effect. The scores of the Downs and Black ${ }^{12}$ checklist can be grouped into four quality levels: $\leq 14$; poor; $15-19$, fair; $20-25$, good; and 26-28, excellent. ${ }^{13,14}$

\section{Data Extraction}

The authors independently extracted data from the included studies. Disagreements were discussed until con- 
sensus was reached. Data from the articles were extracted in a structured table format according to the following topics: first author's last name and year of publication, study design, participants' characteristics, type of intervention(s) or comparator(s) (if there were any), outcome measures used, and quantitative findings.

\section{Data Analysis}

To determine the consistency of the quality assessment performed by the 2 authors, an inter-observer agreement analysis using Cohen's kappa was performed. The value of Cohen's kappa ranges from 0 to 1 , and can be categorized as slight $(0.0-0.20)$, fair $(0.21-0.40)$, moderate $(0.41-$ $0.60)$, substantial $(0.61-0.80)$, or almost perfect $(\geq 0.81)$ agreement. ${ }^{15}$ This statistical analysis was performed using PASW Statistics (version 18.0, SPSS, Chicago, Illinois).

Because of the different designs and outcome measures used in the selected studies a meta-analysis was not possible to conduct. To analyze the effects of pulmonary rehabilitation on mild COPD, the effect sizes were computed for the outcomes of interest. The effect sizes were interpreted as low (0.20), medium (0.50), and high (0.80) effect magnitudes. ${ }^{16}$ All quantitative data analyzes were performed using the software Comprehensive Meta-Analysis version 2 (Biostat, Englewood, New Jersey). ${ }^{17}$

\section{Results}

\section{Study Selection}

The databases search identified 5,728 records. After the removal of duplicate records, 4,766 records were screened for relevant content. During the title, abstract, and keyword screening, 4,745 articles were excluded. The full text of 21 potentially relevant articles was assessed, and 11 articles were excluded for the following reasons: (1) patients with mild COPD were not included $(n=8)$; (2) the effect of pulmonary rehabilitation programs was not assessed with the outcome measures of interest $(n=1)$; (3) quantitative data were not provided $(n=1)$; and (4) the study was not written in English, Portuguese, or Spanish $(n=1)$. Ten studies were retained. Eight of these studies included patients with mild COPD; however, results were not presented by COPD grade. The corresponding authors were contacted to provide data on patients with mild COPD. Only Liu et al ${ }^{18}$ made available the requested data, and therefore their study was included. The other 7 studies were excluded. Therefore, 3 original articles were included. The search for relevant articles within the reference list of the selected articles did not retrieve any further study (Fig. $1)$.

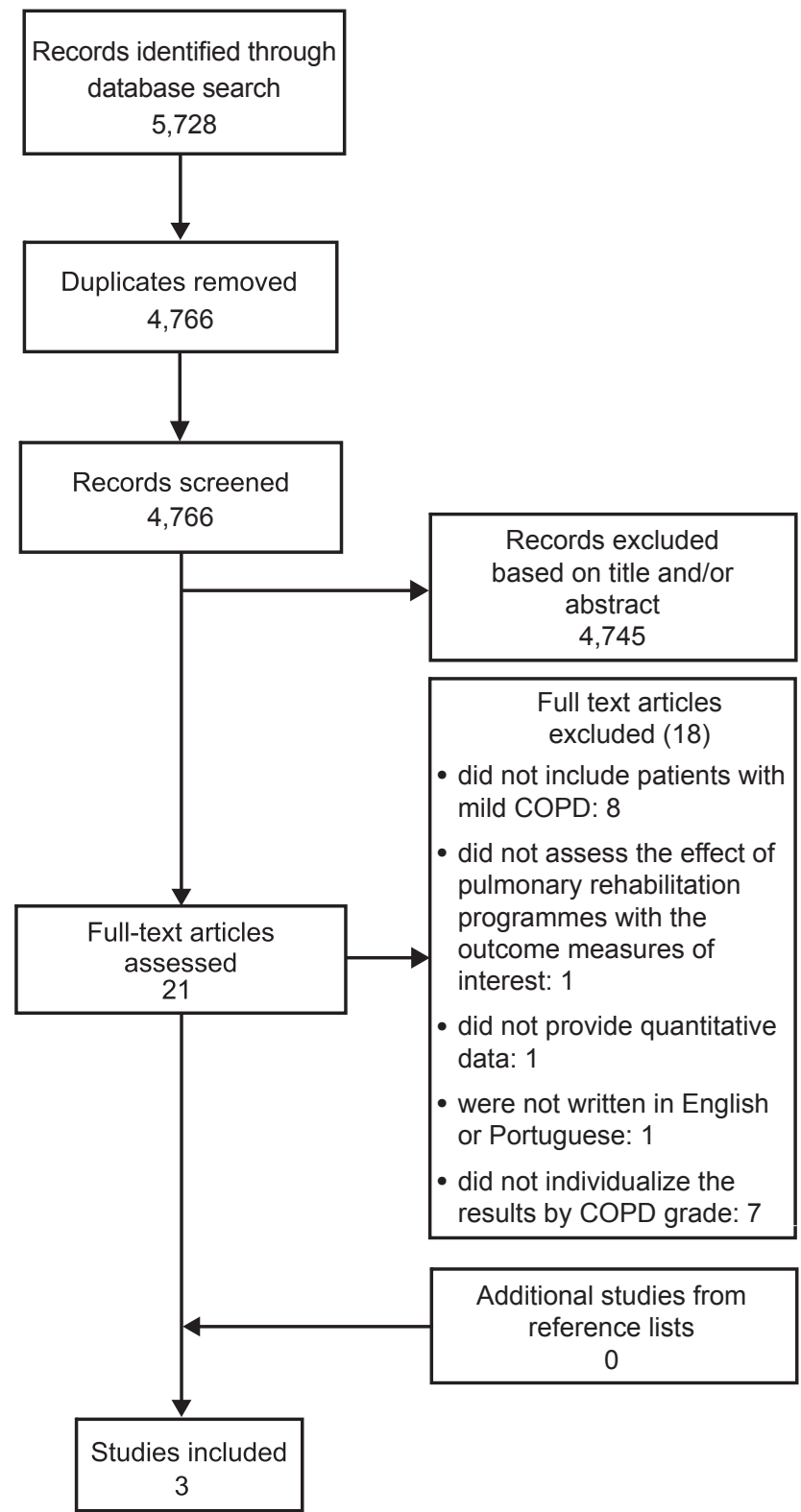

Fig. 1. Flowchart of included studies.

\section{Quality Assessment}

The articles included in this review scored 14-20 on the Downs and Black ${ }^{12}$ scale with a mean of $16.7 \pm 3.1$ (Table 1). The agreement between the 2 authors was substantial $($ kappa $=0.686,95 \%$ CI 0.507-0.842, $P=.001)$. Results indicate that the quality of the studies varied among poor, ${ }^{19}$ fair, ${ }^{20}$ and good..$^{18}$ The 3 studies scored particularly poorly in the following items: description of adverse events, sample representativeness, patient and assessor blinding, adjustment for confounding factors in the analysis, and power. 
Table 1. Quality Assessment Using the Downs and Black ${ }^{12}$ Scale

\begin{tabular}{|c|c|c|c|c|c|c|c|c|c|c|c|c|c|c|c|c|c|c|c|c|c|c|c|c|c|c|c|c|}
\hline \multirow{3}{*}{ Studies } & \multirow{2}{*}{\multicolumn{10}{|c|}{ Reporting }} & \multirow{2}{*}{\multicolumn{3}{|c|}{$\begin{array}{l}\text { External } \\
\text { Validity }\end{array}$}} & \multicolumn{13}{|c|}{ Internal Validity } & \multirow{3}{*}{$\frac{\text { Power }}{27}$} & \multirow{3}{*}{ Tota } \\
\hline & & & & & & & & & & & & & & \multicolumn{7}{|c|}{ Bias } & \multicolumn{6}{|c|}{ Confounding } & & \\
\hline & 1 & 2 & 3 & 4 & 5 & 6 & 7 & 8 & 9 & 10 & 11 & 12 & 13 & 14 & 15 & 16 & 17 & 18 & 19 & 20 & 21 & 22 & 23 & 24 & 25 & 26 & & \\
\hline Golmohammadi et al ${ }^{19}$ & 1 & 1 & 1 & 1 & 0 & 1 & 1 & 0 & 1 & 1 & 0 & 0 & 1 & 0 & 0 & 1 & 0 & 1 & 1 & 1 & 0 & 0 & 0 & 0 & 0 & 1 & 0 & 14 \\
\hline Riario-Sforza et al ${ }^{20}$ & 1 & 1 & 1 & 1 & 1 & 1 & 1 & 0 & 0 & 1 & 0 & 0 & 1 & 0 & 0 & 1 & 1 & 1 & 1 & 1 & 1 & 1 & 0 & 0 & 0 & 0 & 0 & 16 \\
\hline Liu et $\mathrm{al}^{18}$ & 1 & 1 & 1 & 1 & 1 & 1 & 1 & 0 & 1 & 1 & 0 & 0 & 0 & 0 & 1 & 1 & 1 & 1 & 1 & 1 & 1 & 1 & 1 & 1 & 0 & 1 & 0 & 20 \\
\hline
\end{tabular}

\section{Study Characteristics}

Study characteristics are presented in Table 2. The included studies had different designs that included retrospective, ${ }^{19}$ one-group pretest-posttest, ${ }^{20}$ and randomized controlled. ${ }^{18}$ The 3 studies recruited a total of 100 patients receiving specialized care. Golmohammadi et al ${ }^{19}$ did not provide data on age and gender ratio of the 31 patients with mild COPD. In the other 2 studies, age ranged from 41 to $83 \mathrm{y}$, and the number of male patients included were approximately double the number of female patients (47: 22).

The pulmonary rehabilitation programs implemented by Golmohammadi et $\mathrm{al}^{19}$ and by Riario-Sforza et al ${ }^{20}$ were both out-patient programs, with duration between 6 and 8 weeks and frequency between 2 and 3 sessions a week. The exercise training sessions lasted between 60 and $90 \mathrm{~min}$, and included mainly aerobic training, strength training, and respiratory muscle training. Both programs included an educational component. Liu et al ${ }^{18}$ implemented a homebased pulmonary rehabilitation program, consisting of 1 week of pursed-lip breathing and aerobic training under the supervision of health professionals followed by 6 months of peer-led walking and participation in ball games for 60 min twice a week. This study also had a control group that received standard medical treatment, consisting of health education and recommendations to exercise by themselves.

\section{Synthesis of the Results}

\section{Exercise Capacity}

Exercise capacity was assessed in 2 studies by the 6-min walk distance. ${ }^{18,20}$ Significant improvements in exercise capacity were found when comparing pretest-posttest data (effect size (ES) 0.87$)^{20}$ and when comparing pulmonary rehabilitation with standard medical treatment (ES 1.82). ${ }^{18}$

\section{HRQOL}

HRQOL was measured in 2 studies using distinct instruments, that is, the St George Respiratory Questionnaire (SGRQ) ${ }^{19}$ and the Zhongshan COPD questionnaire. ${ }^{18} \mathrm{~A}$ small improvement in SGRQ symptoms (ES 0.34) and activity (ES 0.49) scores, and a medium improvement in SGRQ impact score (ES 0.66) were found after pulmonary rehabilitation. ${ }^{19}$ A significant improvement in HRQOL (Zhongshan COPD questionnaire total score) favored the pulmonary rehabilitation group (ES 0.86). ${ }^{18}$ The Zhongshan COPD questionnaire also provided information on 4 subscales of HRQOL: activity of daily living, social participation, depression, and anxiety. Improvements in anxiety (ES 0.85), activity of daily living (ES 0.47), and depression (ES 0.46) favored the pulmonary rehabilitation group. Social participation did not change significantly in any of the groups (ES 0.24).

\section{Health Care Resource Use}

The number of hospitalization days were decreased after pulmonary rehabilitation (ES 0.38). ${ }^{19}$ The number of emergency department visits also decreased (ES 0.32). ${ }^{19}$ The number of hospitalizations in the pulmonary rehabilitation group after 6 months was not significantly different from that of the control group (ES 0.22). ${ }^{18}$

\section{Lung Function}

Pulmonary rehabilitation had no significant effect on lung function (ES 0.2). ${ }^{18}$

\section{Discussion}

Most of the pulmonary rehabilitation programs implemented in the 3 studies analyzed had significant positive effects on the exercise capacity and HRQOL of patients with mild COPD. However, the effects of these programs on health-care resource use and lung function were inconclusive.

Two studies ${ }^{18,20}$ analyzed the impact of pulmonary rehabilitation on exercise capacity with the 6-min walk test, and a statistically significant improvement was found. The improvement in the distance walked after pulmonary rehabilitation was $\sim 37 \mathrm{~m}$ in one study ${ }^{18}$ and $63 \mathrm{~m}$ in the other. ${ }^{20}$ Since the minimally important difference for the 6-min walk test is expected to be between 25 and $35 \mathrm{~m}$ in patients with moderate and severe COPD, ${ }^{21,22}$ we can hypothesize that in both studies the clinically important effect was achieved. Nevertheless, this has to be interpreted 


\section{Pulmonary Rehabilitation for Mild COPD}

Table 2. Impact of Pulmonary Rehabilitation Programs in Patients With Mild COPD

\begin{tabular}{|c|c|c|c|c|c|}
\hline Studies & Design & Participants & Intervention & Outcome Measures & Findings \\
\hline $\begin{array}{l}\text { Golmohammadi } \\
\text { et al }{ }^{19}(2004)\end{array}$ & Retrospective & $\begin{array}{l}31 \text { patients with } \\
\text { mild COPD }\end{array}$ & $\begin{array}{l}\text { Setting: out-patient } \\
\text { Duration: } 6 \text { or } 8 \mathrm{wk} \\
\text { Frequency: } 2 \text { or } 3 \text { times/wk } \\
\text { Exercise training } \\
\text { Duration: } 90 \mathrm{~min} \\
\text { Components: breathing exercises, } \\
\text { endurance training, upper extremity } \\
\text { strength training, inspiratory muscle } \\
\text { training } \\
\text { Education: adaptations in activities of } \\
\text { daily living, relaxation techniques, } \\
\text { nutritional counseling, psychosocial } \\
\text { support. }\end{array}$ & $\begin{array}{l}\text { SGRQ symptoms } \\
\text { SGRQ activity } \\
\text { SGRQ impact } \\
\text { Emergency } \\
\text { department visits } \\
\text { Hospitalization days }\end{array}$ & $\begin{array}{l}\text { SGRQ symptoms: Pre } 48.3 ; \text { Post } \\
\text { 42.3; } P=.07 \\
\text { SGRQ activity: Pre } 55.3 ; \text { Post } \\
\text { 48.7; } P=.01 \\
\text { SGRQ impact: Pre } 30.8 ; \text { Post } 23 ; \\
P=.01 \\
\text { Emergency department visits: Pre } \\
41.2 \pm 13 ; \text { Post } 13.6 \pm 7.9 ; \\
P=.085 \\
\text { Hospitalization days: Pre } \\
123.9 \pm 75 ; \text { Post } 12.9 \pm 12.9 ; \\
P=.043\end{array}$ \\
\hline $\begin{array}{l}\text { Riario-Sforza } \\
\text { et } \mathrm{al}^{20}(2009)\end{array}$ & $\begin{array}{l}\text { One group } \\
\text { Pretest- } \\
\text { posttest }\end{array}$ & $\begin{array}{l}37 \text { patients with } \\
\text { mild COPD } \\
24 \mathrm{M}, 13 \mathrm{~F} \\
64.6 \pm 9.8 \\
(41-83) \mathrm{y}\end{array}$ & $\begin{array}{l}\text { Setting: out-patient } \\
\text { Duration: } 6 \mathrm{wk} \\
\text { Frequency: } 2 \text { times/wk } \\
\text { Exercise training } \\
\text { Duration: } 90 \mathrm{~min} \\
\text { Components: warm-up, endurance } \\
\text { training, strength training of the arm, } \\
\text { shoulder and trunk muscle groups; } \\
\text { respiratory muscle training. } \\
\text { Education }\end{array}$ & 6MWD & $\begin{array}{l}\text { 6MWD: Pre } 355 \pm 63 \mathrm{~m} \text {; Post } \\
418 \pm 78 \mathrm{~m}\end{array}$ \\
\hline $\begin{array}{l}\text { Liu et al }{ }^{18} \\
\quad(2012)\end{array}$ & $\mathrm{RCT}$ & $\begin{array}{l}\text { Experimental } \\
\text { group } \\
15 \text { patients with } \\
\text { mild COPD } \\
10 \mathrm{M}, 5 \mathrm{~F} \\
56.4 \pm 8.2 \\
\quad(46-72) \text { y } \\
\\
\text { Control group } \\
17 \text { patients with } \\
\text { mild COPD } \\
13 \mathrm{M}, 4 \mathrm{~F} \\
58.9 \pm 6 \\
(46-67) \text { y }\end{array}$ & $\begin{array}{l}\text { Experimental group } \\
\text { Setting: Home-based } \\
\text { Duration: } 6 \text { mo } \\
\text { Frequency: } 2 \text { times/wk } \\
\text { Exercise training } \\
\text { Duration: } 60 \mathrm{~min} \\
\text { Components: walking and participation in } \\
\text { ball games } \\
\text { Education: pursed-lip breathing, aerobic } \\
\quad \text { exercises. } \\
\text { Control group } \\
\text { Standard medical treatment: health } \\
\text { education, advised to continue } \\
\text { exercising. }\end{array}$ & $\begin{array}{l}\text { 6MWD } \\
\text { Zhongshan COPD } \\
\text { questionnaire: } \\
\text { ADL } \\
\text { Anxiety } \\
\text { Depression } \\
\text { Social participation } \\
\text { Total score } \\
\text { Hospitalizations due } \\
\text { to AECOPD } \\
\text { FEV }_{1}\end{array}$ & $\begin{array}{l}\text { Experimental group } \\
\text { 6MWD: Pre } 407.4 \pm 16.9 ; \text { Post } \\
\text { 444.6 } \pm 22.5 ; P=.001 \\
\text { Zhongshan COPD questionnaire } \\
\text { ADLs: Pre } 22 \pm 3.1 ; \text { Post } \\
19.5 \pm 2.7 ; P=.001 \\
\text { Anxiety: Pre } 13.9 \pm 2.4 ; \text { Post } \\
12.3 \pm 1.7 ; P=.002 \\
\text { Depression: Pre } 12.3 \pm 1.7 ; \text { Post } \\
11.1 \pm 1.4 ; P=.011 \\
\text { Social participation: Pre } \\
12.7 \pm 2.5 ; \text { Post } 12.7 \pm 1.9 ; \\
P=.82 \\
\text { Total Score: Pre } 60.8 \pm 5.4 ; \text { Post } \\
\text { 55.7 } \pm .8 ; P=.001 \\
\text { Hospitalizations: Pre } 1.2 \pm 0.4 ; \\
\text { Post } 1 \pm 0.4 ; P=.082 \\
\text { FEV } 1: \text { Pre } 87.2 \pm 4.1 \% \text { predicted; } \\
\text { Post } 87.5 \pm 3.7 \% \text { predicted; } \\
P=.442 \\
\text { Control group } \\
\text { 6MWD: Pre } 403.1 \pm 21 ; \text { Post } \\
\text { 401.6 } \pm 26.7 ; P=.756 \\
\text { Zhonghan COPD questionnaire } \\
\text { ADL: Pre } 21.3 \pm 3.2 ; \text { Post } \\
\text { 20.8 } \pm 2.8 ; P=.324 \\
\text { Anxiety: Pre } 14 \pm 2.9 ; \text { Post } \\
14.35 \pm 2.9 ; P=.496 \\
\text { Depression: Pre } 12.1 \pm 2.0 ; \text { Post } \\
11.9 \pm 2 ; P=.699 \\
\text { Social participation: Pre } \\
12.7 \pm 2.5 ; \text { Post } 12.2 \pm 2.3 ; \\
P=.245 \\
\text { Total score: Pre } 60.1 \pm 4 ; \text { Post } \\
59.2 \pm 3.3 ; P=.440 \\
\text { Hospitalizations: Pre } 1.3 \pm 0.6 ; \\
\text { Post } 1.1 \pm 0.5 ; P=.083 \\
\text { FEV }: \text { Pre } 87.7 \pm 5 \% \text { predicted; } \\
\text { Post } 86.7 \pm 4.3 \% \text { predicted; } \\
P=.221\end{array}$ \\
\hline $\begin{array}{l}\text { Data are presented a } \\
\mathrm{SGRQ}=\text { St George } \\
\mathrm{M}=\text { male } \\
\mathrm{F}=\text { female } \\
\mathrm{RCT}=\text { randomized } \\
6 \mathrm{MWD}=6 \text {-min wal } \\
\mathrm{ADLs}=\text { activities of } \\
\mathrm{AECOPD}=\text { acute ex } \\
\text { Pre }=\text { pretest } \\
\text { Post }=\text { post-test }\end{array}$ & $\begin{array}{l}\text { nean } \pm \text { SD. } \\
\text { spiratory Questionn } \\
\text { trolled trial } \\
\text { listance } \\
\text { ily living } \\
\text { erbation of COPD }\end{array}$ & & & & \\
\hline
\end{tabular}


with caution, as the minimally important difference for the 6-min walk distance in patients with mild COPD has not been established.

The HRQOL was assessed using 2 instruments: the SGRQ $^{19}$ and the Zhongshan COPD questionnaire. ${ }^{23}$ In the study of Golmohammadi et al, ${ }^{19}$ the improvements were all statistically significant, with the exception of the SGRQ symptoms domain. Lacasse et $\mathrm{al}^{5}$ and Puhan et al, ${ }^{24}$ reviewing the benefits of pulmonary rehabilitation in patients with COPD, also verified that the results of the SGRQ symptoms domain were not statistically significant. These findings suggest that this SGRQ domain may be the less responsive to pulmonary rehabilitation programs. In the study of Liu et al ${ }^{18}$ statistically significant improvements in HRQOL favored pulmonary rehabilitation in comparison with the standard medical treatment. The pulmonary rehabilitation programs implemented in the studies by Liu et $\mathrm{al}^{18}$ and Golmohammadi et al ${ }^{19}$ improved the HRQOL of patients with mild COPD. Because physical activity levels and HRQOL can be impaired in patients with mild COPD, ${ }^{7,8}$ and the limited evidence available shows that these health domains can be improved with pulmonary rehabilitation programs, more studies with robust study designs are needed to establish these benefits at an early stage of the disease.

Prevention of respiratory exacerbations is one of the major goals of COPD management. ${ }^{24}$ The effects of pulmonary rehabilitation on the number of exacerbations was not directly assessed in any of the included studies, instead health-care resource use was examined. Pulmonary rehabilitation did not have a statistically significant effect on the number of hospitalizations when compared with standard medical treatment. ${ }^{18}$ A statistically significant decrease in the number of emergency department visits after pulmonary rehabilitation was also not found; however, a significant decrease in the number of hospitalization days was observed. ${ }^{19}$ In patients with mild COPD, the role of pulmonary rehabilitation in preventing exacerbations and its severity remains unclear. This is mainly due to the lack of studies, but probably is also due to the implementation of pulmonary rehabilitation programs with distinct training regimens and therefore different effects of dosage. ${ }^{25}$

Pulmonary rehabilitation had no effect on lung function. ${ }^{18}$ This was expected because previous studies ${ }^{26,27}$ have shown that no changes in lung function were observed in patients with moderate-to-very-severe COPD after conventional pulmonary rehabilitation programs. However, a matched controlled trial performed in patients with moderate and severe COPD shows that after $3 \mathrm{y}$ of out-patient pulmonary rehabilitation the decline in $\mathrm{FEV}_{1}$ was significantly lower in the pulmonary rehabilitation group compared with the control group (standard treatment). ${ }^{28} \mathrm{In}$ patients with mild COPD, it is still unknown whether in the long run pulmonary rehabilitation can delay the de- cline of lung function and therefore disease progression. This needs to be investigated in well-designed longitudinal studies.

This review has important limitations that need to be considered. First, only 3 studies with small sample sizes were included, and the oldest study was published in 2004. This may be because of the difficulty in recruiting patients with mild COPD, because most of them are asymptomatic and do not look for medical assistance. Additionally, this may be a result of the relatively new interest in pulmonary rehabilitation research in mild COPD and of publication bias (studies with statistically significant results are more likely to be published than those with nonsignificant results). Second, a number of well-designed studies including patients with mild COPD were excluded as results were not individualized by COPD grade. The inclusion of these studies would probably consolidate the findings of this review. Third, all studies had different methodological designs and implemented different pulmonary rehabilitation programs regarding the setting, duration, and components. This might be due to the absence of specific guidelines for pulmonary rehabilitation programs for patients with mild COPD. Further research from randomized controlled trials is therefore needed to define the most appropriate specificities of pulmonary rehabilitation for this population. Fourth, mainly the short-term effects of pulmonary rehabilitation were assessed. Only Golmohammadi et al ${ }^{19}$ analyzed the benefits of pulmonary rehabilitation in terms of emergency department visits and hospitalization days $1 \mathrm{y}$ after pulmonary rehabilitation. However, the long-term benefits of pulmonary rehabilitation in terms of exercise capacity and HRQOL for patients with mild COPD remains uncertain. Therefore, long-term studies are also required.

\section{Conclusions}

Most of the pulmonary rehabilitation programs implemented in the included studies had significant positive effects on the exercise capacity and HRQOL of patients with mild COPD. Nevertheless, the effects of these programs on health-care resource use and lung function were inconclusive. This systematic review suggests that patients with mild COPD may benefit from pulmonary rehabilitation as part of the management of their disease; however, insufficient evidence is still available. Further research with robust study designs and longer follow-up times is urgently needed to inform guidelines for pulmonary rehabilitation in patients with mild COPD.

\section{ACKNOWLEDGMENTS}

We thank Dr Bobby Hin-Po Ng and co-workers, who kindly provided additional data regarding their study. 


\section{Pulmonary Rehabilitation for Mild COPD}

\section{REFERENCES}

1. Miravitlles M, Murio C, Guerrero T, Gisbert R. Costs of chronic bronchitis and COPD. Chest 2003;123(3):784-791.

2. Hilleman DE, Dewan N, Malesker M, Friedman M. Pharmacoeconomic Evaluation of COPD. Chest 2000;118(5):1278-1285.

3. Nici L, Donner C, Wouters E, Zuwallack R, Ambrosino N, Bourbeau J, et al. American Thoracic Society/European Respiratory Society Statement on Pulmonary Rehabilitation. Am J Respir Crit Care Med 2006;173(12):1390-1413.

4. Martín-Valero R, Cuesta-Vargas AI, Labajos-Manzanares MT. Types of physical exercise training for COPD patients. In: Ong DK-C, editor. Chronic obstructive pulmonary disease: current concepts and practice. Rijeka, Croatia: InTech; 2012:351-374.

5. Lacasse Y, Goldstein R, Lasserson TJ, Martin S. Pulmonary rehabilitation for chronic obstructive pulmonary disease. Cochrane Database Syst Rev 2006;(4):CD003793.

6. Vestbo J, Hurd SS, Agustí AG, Jones PW, Vogelmeier C, Anzueto A, et al. Global strategy for the diagnosis, management, and prevention of chronic obstructive pulmonary disease. Am J Respir Crit Care Med 2013;187(4):347-365.

7. Shrikrishna D, Patel M, Tanner RJ, Seymour JM, Connolly BA, Puthucheary ZA, et al. Quadriceps wasting and physical inactivity in patients with COPD. Eur Respir J 2012;40(4):1115-1122.

8. Maltais F, Dennis N, Chan CK. Rationale for earlier treatment in COPD: a systematic review of published literature in mild-to-moderate COPD. COPD 2013;10(1):79-103.

9. Chavannes N, Vollenberg JJ, van Schayck CP, Wouters EF. Effects of physical activity in mild to moderate COPD: a systematic review. Br J Gen Pract 2002;52(480):574-578.

10. Schardt C, Adams M, Owens T, Keitz S, Fontelo P. Utilization of the PICO framework to improve searching PubMed for clinical questions. BMC Med Inform Decis Mak 2007;7(1):16.

11. Moher D, Liberati A, Tetzlaff J, Altman DG, on behalf of the PRISMA Group. Preferred reporting items for systematic reviews and metaanalyses: the PRISMA statement. Ann Intern Med 2009;151(4):264269.

12. Downs SH, Black N. The feasibility of creating a checklist for the assessment of the methodological quality both of randomised and non-randomised studies of health care interventions. J Epidemiol Community Health 1998;52(6):377-384.

13. Chudyk AM, Jutai JW, Petrella RJ, Speechley M. Systematic review of hip fracture rehabilitation practices in the elderly. Arch Phys Med Rehabil 2009;90(2):246-262.

14. Samoocha D, Bruinvels DJ, Elbers NA, Anema JR, van der Beek AJ. Effectiveness of web-based interventions on patient empowerment: a systematic review and meta-analysis. J Med Internet Res 2010;12(2): e23.
15. Landis JR, Koch GG. The measurement of observer agreement for categorical data. Biometrics 1977;33(1):159-174.

16. Cohen J. Statistical power analysis for the behavioral sciences. Hillsdale, NJ: Erlbaum; 1988.

17. Borenstein M, Hedges L, Higgins J, Rothstein H. Comprehensive meta-analysis version 2.0. Englewood, NJ: Biostat; 2005.

18. Liu XD, Jin HZ, Ng BHP, Gu YH, Wu YC, Lu G. Therapeutic effects of qigong in patients with COPD: a randomized controlled trial. Hong Kong J Occup Ther 2012;22(1):38-46.

19. Golmohammadi K, Jacobs P, Sin DD. Economic evaluation of a community-based pulmonary rehabilitation program for chronic obstructive pulmonary disease. Lung 2004;182(3):187-196.

20. Riario-Sforza GG, Incorvaia C, Paterniti F, Pessina L, Caligiuri R, Pravettoni $\mathrm{C}$, et al. Effects of pulmonary rehabilitation on exercise capacity in patients with COPD: a number needed to treat study. Int J Chron Obstruct Pulmon Dis 2009;4:315-319.

21. Holland AE, Hill CJ, Rasekaba T, Lee A, Naughton MT, McDonald CF. Updating the minimal important difference for six-minute walk distance in patients with chronic obstructive pulmonary disease. Arch Phys Med Rehabil 2010;91(2):221-225.

22. Puhan MA, Mador MJ, Held U, Goldstein R, Guyatt GH, Schünemann HJ. Interpretation of treatment changes in 6-minute walk distance in patients with COPD. Eur Respir J 2008;32(3):637-643.

23. Cai Y, Li Z, Fang Z. Assessing quality of life among patients with chronic obstructive pulmonary diseases [in Chinese]. Chinese J Gen Pract 2004;3(4):225-227.

24. Puhan MA, Gimeno-Santos E, Scharplatz M, Troosters T, Walters $\mathrm{EH}$, Steurer J. Pulmonary rehabilitation following exacerbations of chronic obstructive pulmonary disease. Cochrane Database Syst Rev 2011;(10):CD005305.

25. Martín-Valero R, Cuesta-Vargas A, Labajos-Manzanares M. Revisión de ensayos clínicos sobre rehabilitación respiratoria en enfermos pulmonares obstructivos crónicos. Rehabilitación 2010;44(2):158166.

26. Zwick RH, Burghuber OC, Dovjak N, Hartl S, Kossler W, Lichtenschopf A, et al. The effect of one year outpatient pulmonary rehabilitation on patients with COPD. Wien Klin Wochenschr 2009; 121(5-6):189-195.

27. Niederman MS, Clemente PH, Fein AM, Feinsilver SH, Robinson DA, Ilowite JS, et al. BEnefits of a multidisciplinary pulmonary rehabilitation program. improvements are independent of lung function. Chest 1991;99(4):798-804.

28. Stav D, Raz M, Shpirer I. Three years of pulmonary rehabilitation: inhibit the decline in airflow obstruction, improves exercise endurance time, and body-mass index, in chronic obstructive pulmonary disease. BMC Pulm Med 2009;9:26. 